\title{
Studies of Induced Chlorophyll Mutations in Lathyrus sativus L.
}

\author{
A. B. Prasad and A. K. Das \\ Mutagenesis and Cytogenetics Laboratory, Botany Department, L. S. College, \\ (University of Bihar), Muzaffarpur-842001, India
}

Received October 24, 1978

The scoring of chlorophyll mutations in $\mathrm{M}_{2}$ generation has been proved to be the most dependable index for evaluating the genetic effects of mutagenic treatments (Gustaffson 1951). This investigations deal with the studies of frequency and spectrum of mutations induced in six varieties by gamma radiation and one variety by both differential and combined treatment of gamma radiation and $0.2 \%$ MES (Methyl Ethane Sulfonate) of Lathyrus sativus L $(2 n=14)$. One previous worker, Nerkar (1976) has also worked on Lathyrus sativus but on varieties other than one studied in the present investigations.

\section{Materials and methods}

Dry and dormant seeds of Lathyrus sativus $\mathrm{L}$. var. $\mathrm{P}_{10}, \mathbf{P}_{24}, \mathrm{P}_{288}, \mathbf{P}_{293}, \mathrm{P}_{585}$ and $\mathrm{LC}_{76}(10 \%$ moisture $)$ were irradiated with $10,20,30,40$ and $50 \mathrm{kR}$ gamma rays at F. C. I., Sindri, India. A detailed description of method of irradiation and post-irradiation treatment and handling has already been described by Prasad and Das-Unpublished.

$\mathbf{M}_{2}$ generation was raised taking ten seeds from each plant and one plant from each fertility group (0-10, 11-20, 21-30, 31-40, 41-50, 51-60, 61-70, 71-80, 81-90 and 91-100). The spectrum of different chlorophyll mutations were recorded per $100 \mathrm{M}_{2}$ plants (Gaul 1960) treatmentwise in each variety. Chlorophyll mutants were classified according to Gustaffson (1940).

\section{Experimental results}

Chlorophyll mutation frequency: Frequency of chlorophyll mutations per $100 \mathrm{M}_{2}$ plants (Gaul 1960) in each variety were scored and presented in histograms (Figs. 1A-G). It appears from the histograms that the chlorohyll mutation frequency increases with increasing dose of ${ }^{60} \mathrm{Co}$ in all varieties, except in $P_{585}$ at $50 \mathrm{kR}$, where it was almost lower only to its immediate lower dose, i.e. $40 \mathrm{kR}$.

$0.2 \%$ MES was found to be more effective than the lowest dose (10 kR) used in the present experiment and it was equal to $20 \mathrm{kR}$ in $\mathbf{P}_{288}$.

Combination treatment of different doses of gamma rays with $0.2 \%$ MES showed increase in chlorophyll mutation with increase in gamma rays doses. It means post-irradiation treatment with $0.2 \%$ MES produce additive effects. 

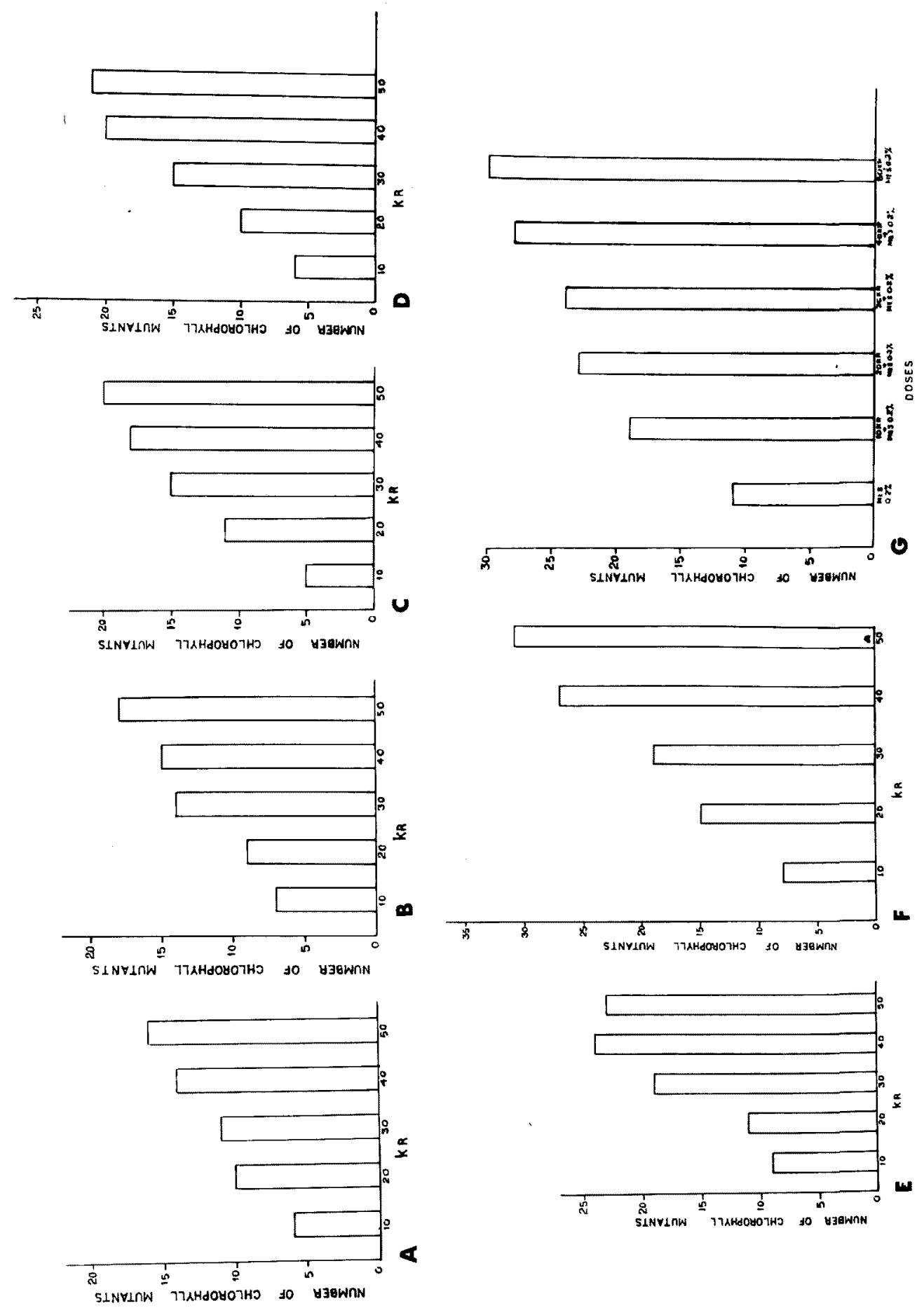
Although response to gamma rays in different varieties differ greatly in relation to frequency of chlorophyll mutations, $\mathrm{LC}_{76}$ appeared to produce more chlorophyll mutants than others.

Frequency and spectrum of chlorophyll mutants: - Frequency of chlorophyll mutant types are summarized in Tables ( $1 \mathrm{~A}-\mathrm{F}$ and 2$)$ and different types of mutations observed are described below:-

1. Albino (A): Seedlings were white in colour and relatively smaller than the normal looking seedlings of the same age. These mutants survived for seven to ten days only.

2. Xantha $(\mathrm{X})$ : Seedlings were straw yellow in colour. They all showed normal growth in the beginning but started withering away on the 10th day and ultimately died within fifteen days.

3. Albo-Xantha (AX): Base of the stem and leaf of the seedlings were yellow. Stem gradually turned green. Leaves showed yellowish base and green tip in an early stage of development, but the tip gradually turned whitish. This type of mutant lived for 30 days and then died.

4. Xanthalba (XA): Seedlings were albino type in the beginning, but later on they become yellowish. Growth of the mutants were less than normal as evidenced from the seedling height. All died within fifteen days, except in $\mathbf{P}_{10}$ at $10 \mathrm{kR}$. Here they survived till flowering but did not set any seeds.

5. Albo-Viridis (AV): Seedlings were quite normal in the beginning but thirty days thereafter the tip of some of the leaves become white. These mutants survived till flowering and also set seeds.

6. Virescence (V): All seedlings which became dark-green at later stage of development, were light green in the early stages. These mutants produced normal looking flower and also set seeds.

7. Chlorina (C): Seedlings were pale yellowish-green to yellowish-green. Most of the yellowish-green type died within thirty days. However, light yellowishgreen types survived till maturity and set a few seeds.

8. Albescence (AS): Original green colour changed gradually to white after ten days. Although this mutant was recorded only in $P_{10}$ at $30 \mathrm{kR}$ and in $P_{288}$ at 20 and $50 \mathrm{kR}$, none of them set any seeds.

9. Tigrina $(T)$ : This mutant had characteristic transverse yellowish and whitish bands on their leaves and had survived till maturity. They produced a few seeds.

10. Maculata (M): Seedlings showed yellow or whitish dots on their leaves and sometimes on stem too. These mutants survived till maturity and set seeds.

A perusal of the Tables ( $1 \mathrm{~A}-\mathrm{F}$ and 2$)$ revealed that gamma rays produced the highest frequency of xantha, chlorina and virescence in all the varieties but MES alone produced maximum number of chlorina followed by xantha, virescence,

Figs. A-G. A-B, chlorophyll mutations induced after ${ }^{60} \mathrm{Co}$ irradiation in six varietes of Lathyrus sativus $\mathrm{L}$. in $\mathrm{M}_{2}$ generation. $A$, var. $\mathrm{P}_{10} . \mathrm{B}$, var. $\mathrm{P}_{24}$. $\mathrm{C}-\mathrm{D}$, chlorophyll mutations induced after ${ }^{10} \mathrm{Co}$ irradiation in six varieties of Lathyrus sativus $\mathrm{L}$. in $\mathbf{M}_{2}$ generation. $\mathrm{C}$, var. $\mathbf{P}_{288} . \mathrm{D}$, $\mathrm{E}-\mathrm{G}$, chlorophyll mutations induced after ${ }^{80} \mathrm{Co}$ irradiation in six varieties of Lathyrus sativus $\mathrm{L}$. in $M_{2}$ generation. $E$, var. $P_{88 s} . F$, var. LC $76 . G$, chlorophyll mutations after differential and combined treatment of ${ }^{80} \mathrm{Co}$ and $0.2 \% \mathrm{MES}$ in $\mathrm{M}_{2}$ generation (var. $\mathrm{P}_{288}$ ). 
tigirina and maculata but no albino. Albino was commonly found only in gamma rays and post-irradiation treatment with $0.2 \%$ MES. However, the frequency of albino was noted to be more than the albo-viridis and albo-xantha, and less than xantha and chlorina in gamma rays treated population.

Table 1. Spectrum of chlorophyll mutations in six different varieties of Lathyrus sativus $\mathrm{L}$.

\begin{tabular}{|c|c|c|c|c|c|c|c|c|c|c|c|}
\hline \multirow{2}{*}{$\begin{array}{l}\text { Doses } \\
\text { (kR) }\end{array}$} & \multirow{2}{*}{$\begin{array}{c}\text { Total } \\
\text { number } \\
\text { of } \\
\text { plants } \\
\text { scored }\end{array}$} & \multicolumn{10}{|c|}{ Mutants types } \\
\hline & & A & $\mathrm{x}$ & $\mathrm{AX}$ & $\mathrm{XA}$ & AV & V & $\mathrm{C}$ & AS & $\mathbf{T}$ & $\mathbf{M}^{*}$ \\
\hline \multicolumn{12}{|c|}{ (A) $P_{10}$} \\
\hline 10 & 100 & 1 & 2 & - & 1 & - & 2 & 一 & 一 & - & - \\
\hline 20 & 130 & 2 & 3 & - & 2 & - & 1 & 2 & - & - & - \\
\hline 30 & 120 & 1 & 2 & 1 & 1 & - & - & 3 & 1 & 1 & 1 \\
\hline 40 & 100 & - & 3 & 1 & 1 & 3 & 1 & 3 & - & 2 & - \\
\hline 50 & 97 & 1 & 3 & - & 2 & 2 & 2 & 3 & 一 & 2 & 1 \\
\hline \multicolumn{12}{|c|}{ (B) $P_{24}$} \\
\hline 10 & 105 & 2 & 1 & - & 2 & - & 1 & 一 & - & 1 & - \\
\hline 20 & 100 & 2 & 2 & - & 1 & 1 & 1 & 2 & - & 一 & - \\
\hline 30 & 189 & 1 & 3 & - & 1 & 2 & 2 & 3 & - & 1 & 1 \\
\hline 40 & 98 & 2 & 1 & 2 & 1 & - & 3 & 2 & - & 3 & 1 \\
\hline 50 & 100 & 4 & 3 & - & 1 & - & 2 & 4 & - & 2 & 2 \\
\hline \multicolumn{12}{|c|}{ (C) $P_{288}$} \\
\hline 10 & 160 & - & 1 & - & 1 & 2 & 1 & - & - & - & - \\
\hline 20 & 180 & 2 & 3 & - & 2 & - & 3 & 1 & - & - & - \\
\hline 30 & 130 & 1 & 3 & 1 & - & 1 & 3 & 2 & 1 & 1 & 3 \\
\hline 40 & 150 & 2 & 2 & 1 & 1 & 3 & 2 & 4 & - & 2 & 1 \\
\hline 50 & 110 & 1 & 4 & 2 & 2 & 4 & 2 & 2 & 3 & 1 & 1 \\
\hline \multicolumn{12}{|c|}{ (D) $\mathbf{P}_{283}$} \\
\hline 10 & 130 & 1 & 2 & - & 1 & - & 1 & 1 & - & - & - \\
\hline 20 & 140 & - & 3 & - & 2 & - & 2 & 1 & - & 2 & - \\
\hline 30 & 150 & 2 & 1 & 1 & - & - & 2 & 3 & - & 2 & 4 \\
\hline 40 & 130 & 2 & 3 & 2 & 2 & - & 3 & 4 & - & 3 & 1 \\
\hline 50 & 97 & 1 & 4 & 3 & 2 & 1 & 2 & 2 & - & 2 & 4 \\
\hline \multicolumn{12}{|c|}{ (E) $\mathbf{P}_{585}$} \\
\hline 10 & 109 & 2 & 1 & 1 & 1 & - & 2 & 1 & - & 1 & - \\
\hline 20 & 125 & - & 2 & 1 & 2 & - & 2 & 2 & - & - & 2 \\
\hline 30 & 104 & 1 & 3 & 1 & 3 & - & 2 & 5 & - & 2 & 2 \\
\hline 40 & 150 & 2 & 5 & 1 & 1 & - & - & 6 & - & 2 & 7 \\
\hline 50 & 98 & 2 & 4 & 1 & 3 & 2 & 1 & 4 & - & 1 & 5 \\
\hline \multicolumn{12}{|c|}{ (F) $\mathrm{LC}_{78}$} \\
\hline 10 & 140 & 2 & 3 & - & 1 & - & 1 & 1 & - & - & - \\
\hline 20 & 130 & 1 & 4 & 1 & 2 & - & 2 & 5 & - & - & - \\
\hline 30 & 140 & 1 & 2 & - & 2 & - & 2 & 5 & - & 2 & 5 \\
\hline 40 & 100 & 1 & 5 & - & 3 & 3 & 2 & 7 & - & 2 & 4 \\
\hline 50 & 103 & 3 & 6 & 1 & 4 & - & 1 & 7 & - & 3 & 6 \\
\hline
\end{tabular}


Table 2. Spectrum of chlorophyll mutations in var. $\mathbf{P}_{288}$ after differential and combined treatment of $0.2 \% \mathrm{MES}+{ }^{\circ 0} \mathrm{Co}$

\begin{tabular}{|c|c|c|c|c|c|c|c|c|c|c|}
\hline $0.2 \%$ MES $\quad 160$ & - & 2 & - & - & - & 2 & 5 & - & 1 & 1 \\
\hline $10 \mathrm{kR}+\mathrm{MES} 150$ & 1 & 4 & 1 & - & 1 & 1 & 6 & - & 3 & 2 \\
\hline $20 \mathrm{kR}+\mathrm{MES} 130$ & 3 & 4 & - & - & - & 1 & 9 & - & 3 & 3 \\
\hline $30 \mathrm{kR}+\mathrm{MES} 140$ & 4 & 7 & - & - & 2 & 1 & 6 & - & 4 & - \\
\hline $40 \mathrm{kR}+\mathrm{MES} 155$ & 1 & 5 & 1 & 1 & 2 & 2 & 7 & - & 2 & 7 \\
\hline $50 \mathrm{kR}+\mathrm{MES} 160$ & 3 & 6 & - & - & 1 & 4 & 7 & - & 3 & 6 \\
\hline
\end{tabular}

* A-Albino, X-Xantha, AX-Alboxantha, XA-Xanthalba, AV-Albo-viridis, V-Virescens, C-Chlorina, AS-Albescens, T-Tigrina, M-Maculata.

The spectrum of chlorophyll mutation showed different frequency in different genotypes. The mutant (pooled data) on the basis of their occurrence in different genotypes could be arranged in the following sequences in decreasing proportion:

\begin{tabular}{|c|c|c|}
\hline Variety & Mutagen & Sequence in decreasing order \\
\hline $\mathbf{P}_{10}$ & ${ }^{80} \mathrm{Co}$ & $\mathrm{X} \rightarrow \mathrm{C} \rightarrow \mathrm{XA} \rightarrow \mathrm{V} \rightarrow\left\{\begin{array}{l}\mathrm{A} \rightarrow \\
\mathrm{T}\end{array} \begin{cases}\mathrm{M} \rightarrow & \mathrm{AS} \\
\mathrm{AX} & \end{cases} \right.$ \\
\hline$P_{24}$ & ", & $\begin{array}{l}\mathrm{A} \rightarrow \mathrm{X} \rightarrow \mathrm{V} \rightarrow \mathrm{XA} \rightarrow \mathrm{M} \rightarrow \mathrm{AV} \\
\mathrm{C}\end{array}$ \\
\hline $\mathbf{P}_{288}$ & ", & $\mathrm{X} \rightarrow \mathrm{V} \rightarrow \mathrm{C} \rightarrow \mathrm{AV} \quad\left\{\begin{array}{l}\mathrm{A} \rightarrow \\
\mathrm{XA}\end{array}\left\{\begin{array}{l}\mathrm{AX} \\
\mathrm{AS} \\
\mathrm{T} \\
\mathrm{M}\end{array}\right.\right.$ \\
\hline $\mathbf{P}_{293}$ & , & $\mathrm{X} \rightarrow \mathrm{C} \rightarrow\left\{\begin{array}{l}\mathrm{V} \rightarrow \mathrm{M} \rightarrow \\
\mathrm{T}\end{array}\left\{\begin{array}{l}\mathrm{A} \rightarrow \mathrm{AV} \\
\mathrm{AX} \\
\mathrm{XA}\end{array}\right.\right.$ \\
\hline$P_{585}$ & ", & $\mathrm{C} \rightarrow \mathrm{M} \rightarrow \mathrm{X} \rightarrow \mathrm{XA} \rightarrow \mathrm{A} \rightarrow \mathrm{V} \rightarrow \quad\left\{\begin{array}{l}\mathrm{AX} \rightarrow \mathrm{AV} \\
\mathrm{T}\end{array}\right.$ \\
\hline $\mathrm{LC}_{76}$ & " & $\mathrm{C} \rightarrow \mathrm{X} \rightarrow \mathrm{M} \rightarrow \mathrm{XA} \rightarrow\left\{\begin{array}{l}\mathrm{A} \rightarrow \mathrm{AV} \rightarrow \mathrm{AX} \\
\mathrm{V}\end{array}\right.$ \\
\hline $\mathbf{P}_{288}$ & $0.2 \% \mathrm{MES}$ & $\mathrm{C} \rightarrow\left\{\begin{array}{l}\mathrm{X} \rightarrow \\
\mathrm{V}\end{array}\left\{_{\mathrm{M}}^{\mathrm{T}}\right.\right.$ \\
\hline
\end{tabular}

\section{Discussion}

Dose dependent increase in the mutation frequency has been reported by Blixt $(1964,1966 a)$ and Nerkar (1976). In the present studies, the frequency of chlorophyll mutations recorded in $\mathrm{M}_{2}$ generation was found to be concomitant with doses. However, this trend was maintained in all the genotypes except in $P_{s 85}$ where at $50 \mathrm{kR}$ it was noted to be lower than $40 \mathrm{kR}$ but higher than rest of other doses.

Several workers have reported higher mutation frequency in legumes following treatments with chemical mutagens as compared to physical mutagens (Blixt et al. 1963, Wellensick 1965, Monti and Donini 1968). In the present investigations $0.2 \%$ MES caused more chlorophyll mutations (cf. Ramana and Natrajan, 
1965) than $10 \mathrm{kR}$ and equal to $20 \mathrm{kR}$ gamma rays in $P_{288}$. It seems, therefore, that $0.2 \%$ MES is more effective than $10 \mathrm{kR}$ and is equal to $20 \mathrm{kR}$ as regards its mutagenic efficiency.

Two mutagens acting in sequence are known to produce additive effects on mutation frequency. This could be expected, if, for example one of the mutagens exposes the previously protected sites for the action of the second mutagens. In case both mutagens compete for the same site, the effects are completly independent of each other. It could either be additive or less than additive. The combined effect of many chemical mutagens have been demonstrated to be more than additive for chlorophyll mutations (Arnason et al. 1963, Favret 1963). Aasveit (1968) found that combination treatment of gamma rays and EMS gave less than additive frequency of chlorophyll mutations as measured on progeny basis and more than additive effects when estimated on $M_{2}$ population basis. The present studies indicate that the combination treatment of gamma rays and MES enhances chlorophyll mutation than their separate treatments.

The varieties also differ in their response to mutagens as measured by estimating the mutation frequency on the basis of $\mathbf{M}_{2}$ population. For example, $\mathrm{LC}_{76}$ gave maximum number of chlorophyll mutations following gamma rays treatment than the other varieties indicating that $\mathrm{LC}_{76}$ is more radiosensitive than other varieties for this character. The mutation frequency and spectrum of mutations have been reported to be controlled by the nature of mutagens as well as genotypic architecture of the varieties in peas by Sidorova (1966). Despite the fact that different frequencies of similar mutations are induced by different mutagens, the chief limiting factor in the induction and recovery of mutations is the genetic constitution of the experimental material (Gregory 1965).

\section{Summary}

Dry and dormant seeds (10\% moisture) of Lathyrus sativus $\mathbf{L}$. var. $\mathbf{P}_{10}$, $\mathrm{P}_{24}, \mathrm{P}_{288}, \mathrm{P}_{293}, \mathrm{P}_{585}$ and $\mathrm{LC}_{76}$ were irradiated with $10,20,30,40$ and $50 \mathrm{kR}$ gamma rays. Both control and irradiated seeds of variety $P_{288}$ was treated with $0.2 \%$ MES for six hours. Albino, Xantha, Albo-Xantha, Xanthalba, Albo-viridis, Virescence, Chlorina, Albescence, Tigrina and Maculata were the general types of chlorohyll mutations observed in all the six varieties at $\mathbf{M}_{2}$ generations.

The spectrum of chlorophyll mutations was found to be dependent on the nature of genotypes. This was further noted to have linear relationship with doses. Maximum chlorohyll mutations were observed in $\mathrm{LC}_{76}$ which was proved to be more sensitive than rest of other varieties.

High frequency of mutations was recorded in $\mathrm{P}_{288}$ as a result of differential and combined treatment of $0.2 \%$ MES which was seen to be as effective as $20 \mathrm{kR}$ gamma rays.

\section{Acknowledgement}

The authors are grateful to F. C. I., Sindri, India for irradiating the seeds and University of Bihar, Muzaffarpur-842001, India for financial assistance. 


\section{References}

Aastveit, K. 1968. Effects of combinations of mutagens on mutation frequency in barly. Mutation in Plantbreeding II. Proc. I.A.E.A. Symp., Vienna: 5-14.

Arnason, T. J., Miocha, J. L. and Laila Mohammed EL-sadak 1963. The effects of some combinations of mutagens on mutation frequency in barley. Genetics today. 1: 93-94.

Blixt, S. 1964. Studies of induced mutations in peas VIII. Ethyleneimine and gamma rays treatments of the variety Witham wonder. Agri. Hort. Genet. 22: 171-183.

-, Ehrenberg, L, and Gelin, O, 1963. Studies of induced mutations in peas VII. Mutation spectrum and mutation rate of different mutagenic agents. Agri. Hort. Genet. 21: 178-216.

- 1966a. Studies of induced mutations in peas XV. Effect of environment on the $X_{1}$ generation of ethyl methane sulfonate treated and gamma irradiated Weitor peas. Agri. Hort. genet. 24: 62-74.

Favret, E. A. 1963. Genetic effects of single and combined treatment of ionizing radiations and ethyl methane sulfonate on barley seeds. Proc. 1st. Int. Barley Genetics Symp., Wegeningen: 68-81.

Gaul, H. 1960. Critical analysis of the methods for determining the mutation frequency after seed treatment with mutagens. Genet. Agraria. 12: 297-318.

Gregory, W. C. 1965. Mutation frequency, magnitude of changes and the probability of improvement in adaptation: In the use of induced mutations in plantbreeding. Rep. FAO/I. A.E.A., Tech. meet. Rome: $429-441$.

Gustaffson, A. 1940. The mutation system of chlorophyll apparatus. Lund. Univ. Arsskr. N. F. $30: 1-40$.

Monti, L. M. and Donini, B. 1968. Response to chronic gamma irradiation of twenty four pea genotypes. Rad. Bot. 8: 473-487.

Nerkar, Y.S. 1976. Mutation studies in Lathyrus sativus. Indian. J. Genet. 32 (2): 223-229.

Ramana, M. S. and Natrajan, A. T. 1965. Studies on the relative mutagenic efficiency of alkylating agents under different conditions of treatment. Indian. J. Genet. 25:24-25.

Sidorova, K. K. 1966. Experimentally induced mutation in peas. Proc. Symp. Prague, Czech. Acad. Sci.: $143-145$.

Wellensiek, S. J. 1965. Comparison of the effects of EMS, neutrons, gamma rays and X-rays on peas. Rad. Bot. (Suppl.) 5: 227-235. 